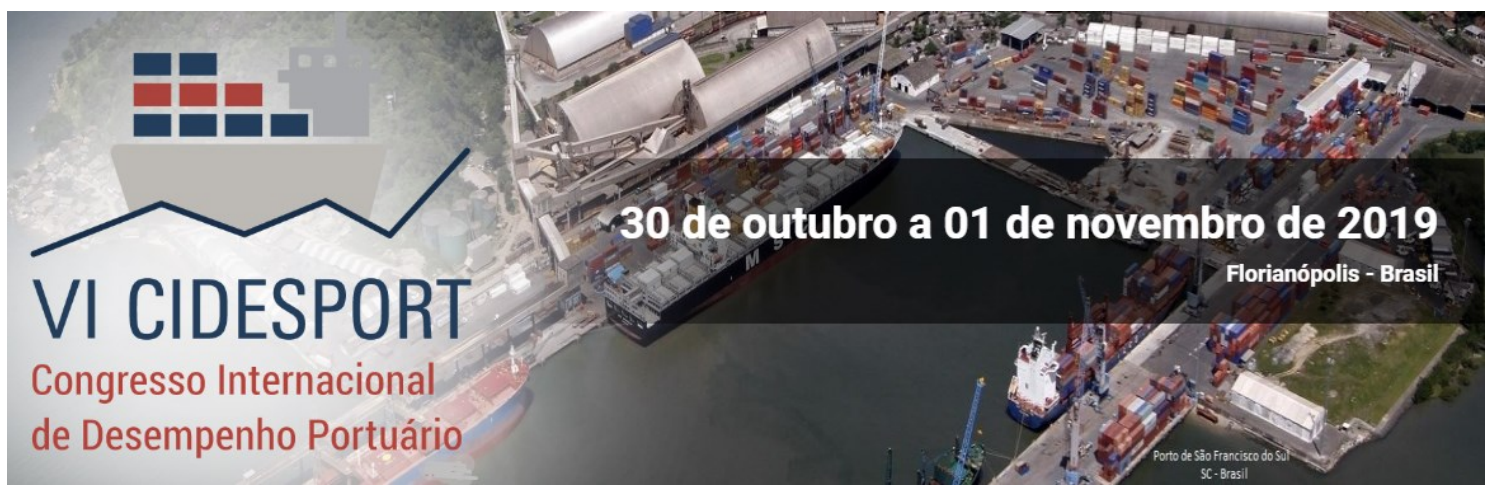

\title{
A PERCEPÇÃO DA RESPONSABILIDADE SOCIAL EMPRESARIAL NA RELAÇÃO DA CODESA E ARRENDATÁRIAS COM A COMUNIDADE DO ENTORNO
}

\author{
Andreia Coutinho e Silva \\ Universidade Vila Velha UVV-ES \\ Adriana Rigoni \\ Universidade Vila Velha UVV-ES \\ Flavia Nico Vasconcelos \\ Universidade Vila Velha UVV-ES \\ Luiza Kister Lucas \\ Universidade Vila Velha UVV-ES
}

Resumo: A comunidade portuária é formada pelas arrendatárias, pelo porto e por todos aqueles que ele interage, em suas diferentes percepções. Este artigo tem como objetivo analisar a relação da CODESA e das arrendatárias com a comunidade do entorno destacando como as características da responsabilidade social se incorporam nessa relação. Trata-se de uma pesquisa com finalidade descritiva, destinada a analisar as relações entre uma entidade portuária e a comunidade do entorno. Para isto, realizou-se entre os meses de outubro a dezembro de 2017 pesquisas de campo com entrevistas à CODESA e arrendatárias a fim de identificar como se estabelece a comunicação entre elas e a comunidade situada no entorno do porto de Vitória. Podese concluir que a CODESA, por ser uma autoridade portuária, disponibiliza canais de comunicação para a comunidade civil do entorno, mas sem realizar ações a partir das demandas dela. Isso também acontece com as arrendatárias, que também demonstram que não possuem relações de proximidade com as comunidades do entorno.

Palavras-Chave: Responsabilidade Social. Porto. CODESA. Arrendatárias. Comunidade civil.

\section{INTRODUÇÃO}

O porto é um instrumento de viabilização econômica dos fluxos de produção com demandas socioeconômicas, que influenciam a vida dos moradores com impactos nos espaços urbanos. Portanto, o porto é um fator de indução do desenvolvimento local e regional, um gerador de empregos contribuindo para o desenvolvimento e crescimento da sociedade. Por outro lado, tem-se a comunidade local que, ao mesmo tempo em que é beneficiada pelas atividades portuárias, também é prejudicada, já que elas impactam diretamente sobre a rotina da população.

\footnotetext{
* A revisão gramatical, ortográfica, ABNT ou APA foi realizada pelos autores.
} 
O complexo portuário de Vitória é administrado pela Companhia Docas do Espírito Santo (CODESA), onde constam o Cais Comercial de Vitória, Terminal da Flexibrás, Cais de Capuaba, Terminal de Vila Velha (TVV), Terminal Peiú e o Terminal Ferro Gusa, Terminal de Granéis Líquidos de São Torquato, Terminal da Companhia Portuária de Vila Velha (CPVV), e o armazém retroportuário Hiper Export. Os Portos representam grande parcela da economia do Estado, responsável em torno de $45 \%$ do PIB capixaba.

A condição do porto de estabelecer sinergias com a comunidade local o transforma em instrumento de desenvolvimento local. Mas será que o complexo portuário de Vitória consegue ter esta sinergia com a comunidade do entorno? $\mathrm{O}$ debate sobre quem surgiu primeiro, o porto ou a cidade, acabou por afastar os dois atores ao invés de contribuir para o desenvolvimento de uma relação forte e de aproveitamento mútuo.

Por isso, a responsabilidade social empresarial, em uma compreensão mais ampla (ASHLEY, 2003), surge como uma possibilidade de atuação conciliatória, uma vez que as empresas se mostram atentas às necessidades da comunidade, usufruindo daquilo que necessitam para crescer, mas ao mesmo tempo, realizando trabalhos e ações que contribuam para a melhoria da qualidade de vida e para o desenvolvimento da comunidade local.

O objetivo deste trabalho é analisar a relação da CODESA e das arrendatárias com a comunidade do entorno destacando como as características da responsabilidade social empresarial se incorporam nessa relação. Para isto, foi realizada pesquisa de campo e entrevistas com a CODESA e arrendatárias para identificar por meio da comunicação utilizada por elas a percepção delas sobre a responsabilidade social da empresa para com a comunidade que fica no entorno do porto.

Este artigo está dividido em cinco seções. Além desta introdução, a segunda seção apresenta o que é a responsabilidade social empresarial e sua influência na atuação das empresas em relação às comunidades em seu entorno, aborda a responsabilidade social empresarial sob a análise de diferentes autores do tema. A terceira seção apresenta a Codesa e arrendatárias. Na quarta seção apresenta a metodologia utilizada na pesquisa e os resultados conseguidos através das entrevistas realizadas com a CODESA e arrendatárias. A quinta seção traz as considerações finais da pesquisa.

\section{RESPONSABILIDADE SOCIAL EMPRESARIAL (RSE)}

As empresas são parte integrante de um sistema econômico. Em sua atividade produtiva utilizam recursos, renováveis e não renováveis, que são patrimônio gratuito e coletivo da sociedade. Devem, por isso, compensar a sociedade por este uso. Uma das formas de compensação são investimentos sociais (REIS, 2007), que podem abarcar projetos das mais diferentes áreas como saúde, educação, meio ambiente e economia (ASHLEY, 2003).

Como detentoras de poder econômico e político, as empresas são capazes de interferir direta ou indiretamente na dinâmica social. Ao assumirem causas sociais, elas estariam pagando uma parte de sua 'dívida social' (MELO NETO; FROES, 1999), devolvendo à sociedade parte dos recursos humanos, naturais, financeiros que consumiram para gerar lucro privado em sua atividade (SCHROEDER, 2004).

Conscientes de que as empresas são portadoras e geradoras de riquezas materiais e poderiam - ou deveriam - assumir mais responsabilidades e contribuir mais 


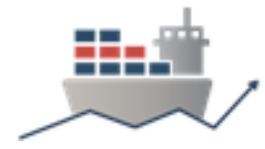

ativamente para a solução de problemas sociais e ambientais, a sociedade passou a ter um papel mais atuante, organizando-se em movimentos civis. Por outro lado, essa mobilização social é também fruto tanto do reconhecimento da falência do Estado como provedor único das necessidades humanas básicas e, por outro lado, devido à própria consciência da escassez de trabalho e emprego. Nesse contexto, articulamse de forma mais consciente e articulada cobrando retornos da empresa. 1984):

Essa tomada de consciência já era preconizada por Marx (apud GUIMARÃES,

O modo de produção da vida material determina o caráter geral dos processos de vida social, política e espiritual. Não é a consciência dos homens que determina sua existência, mas sim o contrário, é sua existência social que determina sua consciência (GUIMARÃES, 1984, p. 1).

Essa "exigência ética" acaba se convertendo em algo bom para a empresa que passa a possuir, o que é definido pelos Sen e Kliksberg (2010), uma forma de se adaptar para o século XXI, já que a sociedade atual age com cobranças as grandes corporações para problemas sociais que podem possivelmente ser causados pela atuação das mesmas evidenciando a mudança de valores da sociedade pós-industrial o que contribuiu, conforme Tenório (2006), para o estabelecimento de um novo conceito para responsabilidade social empresarial:

\begin{abstract}
Nessa nova concepção do conceito, há o entendimento de que as companhias estão inseridas em um ambiente complexo, onde suas atividades influenciam ou têm impacto sobre diversos agentes sociais, comunidade e sociedade. Consequentemente, a orientação do negócio visando atender apenas aos interesses dos acionistas torna-se insuficiente, sendo necessária a incorporação de objetos sociais no plano de negócios, como forma de integrar as companhias à sociedade.
\end{abstract}

O novo conceito amplia o sentido da responsabilidade social empresarial por entender que a firma possui uma função social (SOUZA, 1995, apud TENÓRIO, 2006), incluindo nele a 'responsividade social' cuja ideia central é a de que as empresas "[...] devem responder às demandas sociais para sobreviver, adaptando o comportamento corporativo às necessidades sociais" (BORGES, 2001, p. 44, apud TENÓRIO, 2006).

Portanto, novos desafios gerenciais estão surgindo. Há uma certa emergência por parte das empresas em tomarem medidas para enfrentar os problemas sociais e agirem com responsabilidade social, já que não é mais aceitável conviver com a ideia de grandes avanços em inovações tecnológicas de um lado e a degradação da vida humana do outro (REIS, 2007).

O conceito e concretização das ações de responsabilidade social empresarial (RSE) vem mudando de uma concepção antes baseada na caridade e altruísmo - a filantropia - para uma associação entre responsabilidade social e estratégia empresarial (SMITH, 1994). Esse movimento tem provocado uma mudança de comportamento e de percepção por parte das empresas que tratam a responsabilidade social como uma importante ferramenta para alcançar o sucesso no mercado.

Segundo Melo, Neto e Froes (2001), responsabilidade social é o estágio mais avançado da cidadania corporativa. Suas ações, direcionadas ao desenvolvimento do cidadão, são resultado de uma tomada de consciência do dever para com a sociedade e exigem gerenciamento efetivo por parte da empresa. A filantropia, por sua vez, é voltada para o auxílio aos pobres, desfavorecidos ou excluídos, visando sua 


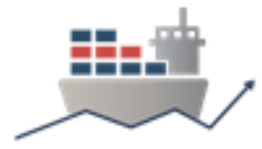

sobrevivência. Suas ações são restritas aos empresários filantrópicos e são vontades individuais dos mesmos, que agem através de doações geralmente a entidades carentes. Portanto, responsabilidade social empresarial é um compromisso com a busca para a solução de problemas sociais e a filantropia é uma doação que surge de um sentimento de sensibilidade do empresário.

Com o aumento da complexidade dos negócios, o empresariado começou a considerar a atuação socialmente responsável como transformadora da sociedade e uma importante forma de vantagem competitiva (ASHLEY, 2003; SERPA, 2007). Afinal, uma empresa que possui ações de responsabilidade social o faz, segundo Porter e Kramer (2006), por vários argumentos como: senso de obrigação moral (empresa cidadã), sustentabilidade, melhor relacionamento com órgãos ambientais e com a sociedade e melhoria da imagem da empresa e agregação de valor à marca.

Davis (apud GUIMARÃES, 1984) argumenta que a responsabilidade social deriva de seu grande poder social. Aponta a importância do papel das empresas na sociedade, considerando que as decisões tomadas por elas possuem amplas consequências sociais e que, portanto, não pode ser motivada apenas por fatores econômicos.

A abordagem socioeconômica de responsabilidade social deve resultar em um novo modelo de gestão de negócios, em que se presume que as decisões tomadas serão éticas e corretas, mostrando que a empresa também se considera responsável pelo processo de desenvolvimento de uma sociedade menos desigual e mais justa, resultando em sustentabilidade da sociedade dos pontos de vista social e econômico (REIS, 2007). Logo, a responsabilidade social pode contribuir de forma decisiva para sustentabilidade.

Por outro lado, a responsabilidade social também tem impactos sobre o desempenho empresarial. Segundo McWillians e Siegel (apud BERTONCELLO, Jr, 2007), a responsabilidade social empresarial é uma importante fonte de diferenciação e de criação de vantagem competitiva. Tem como um dos resultados criar novas demandas por seus produtos/serviços, uma vez que os cidadãos passam a valorizar o que é produzido de forma responsável e se tornam dispostos a arcar com custos a mais de produção que são adicionados ao preço final do produto ou serviços vendidos pelas empresas.

De acordo com Wanderley e Collier (apud GARCIA, 2002), existem três condições que devem ser preenchidas para uma construção de um referencial teórico adequado ao estudo da responsabilidade social empresarial: primeiro, é preciso adotar uma realidade que seja referente ao Brasil, considerando as particularidades de cada sociedade; segundo, por se tratar de um conceito ainda em construção, é necessário construir um referencial flexível, que se adapte em diferentes contextos; por fim, deve-se buscar consistência entre o conceito de responsabilidade social adotado e o referencial teórico em questão.

Apesar do debate existente em relação ao tema e de seu ganho de notoriedade nos dias atuais, ainda não há um consenso quanto ao que seria uma postura de responsabilidade social empresarial. Segundo Bower (1957), o histórico de definições para esse tema é caracterizado por uma certa imprecisão.

Mac Lennan, Semensato e Oliva (2013) afirmam que a RSE pode ser abordada através de três linhas teóricas: a abordagem ética, a abordagem contratual e a abordagem estratégica. A abordagem ética deriva da ética empresarial e é definida por Faria e Sauerbronn (2008) como sendo o julgamento moral das empresas em relação as suas atividades, ou seja, leva em consideração fatores culturais, ideológicos e institucionais. A abordagem contratual possui embasamento 


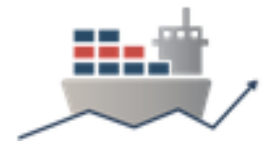

sociopolítico, com questões pragmáticas se apoiando em três pressupostos: o de que a empresa e a sociedade possuem interação constante; de que ambas são racionais e possuem capacidade para chegarem a acordos satisfatórios (contrato social); e de que a empresa pode sofrer controle por parte da sociedade. Essa abordagem diz que a existência da empresa está ligada ao desempenho e cumprimento de certas funções junto à sociedade (KREITLON, 2004). Finalmente, a abordagem estratégica tem como foco "a produção de ferramentas de gestão que sejam capazes de melhorar o desempenho social e ético das empresas" (FARIA, SAUERBRONN, 2008, p. 19). Esta é a abordagem que a empresa utiliza para gerir temas sociais e buscar vantagens competitivas de forma responsável (MAC LENNAN, SEMENSATO, OLIVA, 2013).

Para Albuquerque (2009), existem mais duas abordagens que devem ser apontadas no estudo da RSE, uma ampla e outra estreita. A abordagem ampla compreende as atividades de negócios que vão além do compromisso com o retorno econômico, com uma visão tida como moderna que aposta em ações de responsabilidade social de longo prazo que tragam benefícios para a empresa. Inclui também uma visão filantrópica segundo as quais as ações devem ser praticadas mesmo que não tragam retornos financeiros para a empresa. A abordagem estreita destaca que o objetivo da empresa é, basicamente, o de maximizar o valor para o acionista. Ela pode ter uma visão socioeconômica, que defende que o objetivo da empresa é a maximização do valor gerado para o acionista por meio das ações de responsabilidade social, ou ter uma visão clássica, em que as ações não geram valor para a empresa e então não devem ser desenvolvidas (ALBUQUERQUE, 2009).

De acordo com Sen e Kliksberg (2010), por décadas a visão que se tinha era de que a única responsabilidade das empresas seria a de maximização dos lucros para seus proprietários. Essa visão foi desfeita através da própria realidade prática, que mostrou a atuação das forças sociais interferindo nas atividades empresariais. As exigências da sociedade em relação à responsabilidade social empresarial englobam políticas que respeitam os atores internos da empresa e também que demonstram transparência da governança empresarial para a sociedade. Além disso, a atividade dos cidadãos e o crescimento do consumo responsável traz uma mudança nos paradigmas de RSE, pois forçam as empresas a se preocuparem mais com o meio onde estão instaladas (SEN, KLIKSBERG, 2010).

\section{CODESA E ARRENDATÁRIAS}

O Porto de Vitória foi criado oficialmente em 28 de março de 1906, sob o nome de Companhia Porto de Vitória (CPV). Estudos apontavam sempre que a melhor opção para construção do porto seria do lado da cidade de Vila Velha, porém por razões políticas e econômicas as primeiras obras se iniciaram do lado da llha de Vitória, na região da Vila Rubim (MATTEDI, 2018; VASCONCELOS, 2016). A percepção da importância política e econômica do Porto para a capital de mesmo nome comprovou-se no decorrer dos anos.

O Porto ajudou a dar à cidade a vocação portuária e para o comércio exterior, ao mesmo tempo em que participou dos processos de mudanças econômicas, sociais e urbanas pelas quais a cidade passou (VASCONCELOS, 2011). Ainda hoje é tratado como um porto laboratório, por servir como piloto na experimentação de novas tecnologias, movimentação de cargas e novos instrumentos de gestão.

O Porto de Vitória é administrado pela autoridade portuária federal Companhia Docas do Espírito Santo, a Codesa. Opera com sete terminais de transporte de carga geral, granéis líquidos e granéis sólidos, como alimentos, produtos siderúrgicos, 


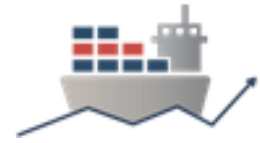

minério de ferro, matérias-primas em geral, fertilizantes, rochas ornamentais, equipamentos eletroeletrônicos, roupas, petróleo, veículos e operações offshore. Seus terminais estão distribuídos nas cidades de Vitória, Vila Velha e Aracruz (CODESA, 2013).

O Porto de Vitória conta com o Cais de Vitória ou Cais Comercial, terminal público voltado para carga geral e atividades offshore em Vitória. Tem também um espaço arrendado à empresa Flexibrás/Technip, conhecido como Terminal da Flexibras/Technip, com estrutura de dolphins, voltado para fabricação e embarque de tubos flexíveis e materiais diversos para atividades offshore.

Do outro lado da Baía de Vitória, no município de Vila Velha, encontra-se um terminal desativado, o Terminal de Granéis Líquidos São Torquato, que atuava com granéis líquidos e derivados do petróleo. Em Vila Velha também está o Cais de Paul, criado em 1959 para movimentação de minério de ferro da atual Vale. Na década de 1990, a Codesa assumiu o terminal que passou a se chamar Terminal de Ferro Gusa, voltado para granéis sólidos e carga geral, que são movimentados através de um contrato operacional com a Multilift Logística. Também neste cais está o Terminal Portuário PEIÚ (TPP), em área leiloada, em 1998, para um consórcio. Atualmente comercializa cargas off-shore, cargas gerais e fertilizantes.

Ainda em Vila Velha, há os terminais do Complexo de Capuaba. Está em construção o Terminal Dolphins de Atalaia, para suprir e dar apoio às operações envolvendo granéis líquidos para exportação, como álcool e melaço. Há ali a Companhia Portuária Vila Velha/CPVV, para prestar serviços ao setor offshore de exploração e produção de petróleo, serviços de base de suprimentos, logística marítima e terrestre além de armazenagem. O Cais de Capuaba conta com o Terminal de grãos que opera produtos agrícolas, carga geral e soda cáustica e o Terminal Vila Velha/TVV para as operações de embarque e descarga de contêineres, navios rollon/roll-off, mármore e granito e carga geral (VASCONCELOS, et al, 2019).

As comunidades que estão no entorno do complexo portuário do Porto de Vitória estão nos dois lados da Baía de Vitória. Do lado de Vitória, a região chamada de Centro, sobretudo nas imediações da Vila Rubim, do Palácio Anchieta até a Praça 80. Em Vila Velha, estão Argolas, São Torquato, Atalaia, Ilha das Flores, Ilha da Conceição, Santa Rita e Zumbi dos Palmares.

\section{METODOLOGIA E RESULTADOS DA PESQUISA}

Utilizando-se a tipologia de Vergara (2017), este artigo é uma pesquisa descritiva quanto aos fins, destinada a identificar e analisar os canais de relacionamentos e as relações construídas entre a administração do porto público Porto de Vitória e as gestoras dos terminais e demais áreas arrendadas situadas no polígono do Porto de Vitória e as comunidades que se situam no entorno físico do Porto. Os dados foram coletados por meio de pesquisa de campo, através de entrevistas semi-estruturadas realizadas presencialmente entre os meses de outubro a dezembro de 2017.

A administração do porto é feita pela CODESA, entidade pública, vinculada ao Ministério de Transportes, Portos e Aviação. A gestão dos portos organizados brasileiros é do tipo landlord port, o que significa que a infraestrutura é provida pelo governo federal, mas a operação pode ser concedida à particulares. A CODESA é a responsável pela gestão dos cais públicos e também pelos contratos de arrendamento e concessão. Desde a Lei 8.630/93, conhecida como Lei de Modernização dos Portos, as autoridades portuárias receberam diretrizes para gerenciamento estratégico do 


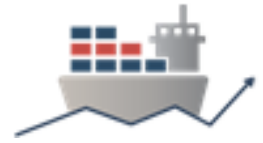

porto, em uma lógica de competição acirrada focando na geração de lucros. Dessa forma, cabe pensar o porto, pelo menos em seu aspecto gerencial, com uma lógica que se assemelha a das empresas privadas.

O porto organizado é representado nessa pesquisa, portanto, pela autoridade portuária com competência pela sua gestão - a Companhia Docas do Espírito Santo (CODESA). Em sua área de localização constam o Cais Comercial de Vitória, o Rhodes (que é um silo da CODESA), Terminal da Flexibrás, Cais de Capuaba, Terminal de Vila Velha (TVV), Terminal Peiú, Terminal Ferro Gusa, Terminal de Granéis Líquidos de São Torquato, Terminal da Companhia Portuária de Vila Velha (CPVV) e o armazém retroportuário Hiper Export. As entrevistas foram realizadas com os setores da presidência, comunicação, marketing e ouvidoria. Buscou-se identificar quais setores são responsáveis pela comunicação com a comunidade civil e como funciona essa comunicação. Como pode-se notar, parte da área do porto está sob a gestão direta da iniciativa privada.

Foram realizadas entrevistas com quatro das dez arrendatárias que aceitaram responder as entrevistas. Entretanto, por solicitação das mesmas, seus nomes foram aqui designadas por letras. As entrevistas foram realizadas com os gestores das arrendatárias a fim de identificar a percepção deles sobre sua responsabilidade empresarial no relacionamento das arrendatárias com a comunidade do entorno imediato, já que é ela que sofre os impactos diretos de suas atividades.

As entrevistas incluíram questões sobre o canal de comunicação disponibilizado pela empresa para a comunidade, a forma como ocorre a comunicação entre as partes, a utilização do canal de comunicação por parte da comunidade e a efetividade dos mesmos em relação às demandas da comunidade.

Iniciou-se, portanto, pela investigação sobre as formas que as empresas utilizam para aproximar-se da comunidade a fim de conhecer suas necessidades e anseios. Para isto, é necessário que as empresas detenham um canal de comunicação de fácil acesso e eficiente. A autoridade portuária CODESA divide sua relação com a comunidade entre os setores de ouvidoria, coordenação de comunicação e marketing.

O setor de ouvidoria possui dois empregados e um deles, o responsável pelo setor, já atua no cargo há quatro anos. Ele funciona por meio de sistema disponibilizado na $W e b$, onde são enviadas, pela comunidade, solicitações de informações ou demandas referentes a denúncias, reclamações e outros. Essa estrutura foi considerada suficiente pelo responsável, em relação ao tamanho da empresa e também à quantidade de demanda.

Além do sistema acima, o representante da CODESA informou que o site da autoridade portuária também disponibiliza acesso para duas plataformas Web de comunicação que o governo desenvolveu para o atendimento à comunidade. Uma foi desenvolvida pelo Ministério da Transparência e Controladoria Geral da União (CGU) e que atende à Lei no 12.527/11 - Lei de Acesso à Informação, que se refere ao e-Sic, para todas as empresas e órgãos. Outra foi desenvolvida pela Advocacia Geral da União (CJU), é a plataforma e-Ouve, que atende demandas de ouvidoria.

Além das possibilidades de comunicação via website, também foi informado que existe a possibilidade de comunicação feita presencialmente e por telefone. Entretanto, esses meios não são frequentemente utilizados, sendo o sistema online o preferido.

Quando inqueridos sobre qual tipo de stakeholder possui mais demanda, ele declarou serem caminhoneiros e operadores portuários. Já os trabalhadores portuários demandam apenas quando surge algum problema ou alguma disfunção do 


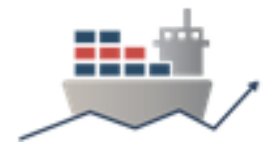

sistema, o que é pouco frequente. A demanda de moradores se dá em função do tipo de atividade que está sendo realizada no Porto. Assim, quando estão sendo realizadas obras de dragagem do canal de acesso do porto na área portuária, a demanda aumenta, já que impacta mais sobre a qualidade de vida da população e afeta o bem-estar da comunidade.

O representante da CODESA também informou que as demandas recebidas nos diversos canais são classificadas e que, em sua maioria, são pedidos de informações sobre contratos, informações acadêmicas para trabalhos e pesquisas, e também pedidos de informações do pessoal interno da empresa, sem excluir reclamações e sugestões.

Quando as demandas estão na alçada da empresa, o prazo legal de resposta é de vinte dias, podendo ser prorrogado para mais dez com justificativa. Caso a resposta não seja dada ou seja considerada insuficiente pelo usuário, este pode entrar com recurso, que deve ser respondido em até cinco dias. Mas quando as demandas não são relacionadas à empresa, eles encaminham para seus respectivos destinatários como, por exemplo, órgãos federais e prefeituras orientando o solicitante a procurar os responsáveis.

A relação entre porto e comunidade, entretanto, vem se tornando cada vez mais próxima na percepção do entrevistado. Assim, ele considera que a comunidade externa começou a aceitar mais o porto como um agente econômico, pois eles sentem que sem o porto a cidade se esvaziaria e poderia 'morrer'. A dimensão econômica da responsabilidade social entra em cena, pois além da empresa conseguir gerar lucros e se manter, ainda consegue passar para a comunidade uma sensação de que sem o porto o desenvolvimento do próprio estado pode cair drasticamente.

O setor de coordenação de comunicação se volta em grande parte para o relacionamento com a imprensa. Ele abrange a ouvidoria - que é responsável pelos telefonemas esclarecendo dúvidas e recebendo reclamações - e o marketing - que é responsável pelas visitas assistidas. A equipe de comunicação é formada por: cinco estagiários de áreas como jornalismo e design gráfico; quatro funcionários e dois menores aprendizes. A infraestrutura da equipe é considerada pequena, mas consegue solucionar todas as demandas, pois são periodicamente treinados $e$ recebem cursos de capacitação oferecidos pela CODESA. O representante informou que recentemente foi proporcionado um treinamento em formação de ouvidoria e também um no Sistema Eletrônico do Serviço de Informações ao Cidadão (e-Sic) que é um Programa do Governo Federal que permite que qualquer pessoa, física ou jurídica, encaminhe pedidos de qualquer tipo, acompanhe prazos e também receba sua resposta.

O setor de comunicação conta, também, com um site institucional da empresa e uma fanpage em uma rede social que servem para melhorar a comunicação com a comunidade. Apesar de tudo isso a comunicação entre porto e comunidade não ocorre de forma direta, pois quem mais estabelece contato direto com a empresa são a imprensa e as agências locais.

Uma alternativa que a responsável pelo setor encontrou para estreitar o relacionamento com a comunidade foi a criação de um varal solidário, onde os funcionários do porto fazem doações de roupas para pessoas que moram nas ruas e necessitam desse tipo de ajuda, não excluindo a participação dos cidadãos que moram ou passam pelas redondezas. Além disso, a iniciativa também engloba a arrecadação de roupas e brinquedos ao fim do ano e 'apadrinhamentos' para ajudar algumas comunidades do entorno. 


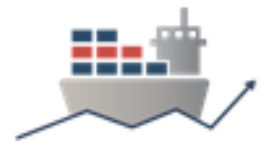

O engajamento externo deste setor mostra que o bem-estar e a melhoria da qualidade de vida da sociedade é uma preocupação para a arrendatária, além de estimular a sociedade a fazer o mesmo.

Uma dificuldade citada pela CODESA foi a de comunicação com outros arrendatários. O representante esclarece que o estabelecimento dessa comunicação é necessário para realização e divulgação de eventos e ações que envolvam todos da comunidade portuária, e é uma relação baseada na confiança, diz a responsável pelo setor.

Dentro da comunicação existe uma preocupação com a integração, principalmente, daqueles que estão direta e indiretamente envolvidos nas operações portuárias. Antes o sentimento que existia era de divisão, como se existissem várias empresas pequenas dentro de uma empresa grande, pois não havia relações interpessoais ou sensação de 'pertencimento'. Percebendo isso, a autoridade portuária realizou um trabalho de aproximação. Uma das estratégias foi a criação e distribuição de um jornal para operadores e agentes, empresas públicas e sindicatos, deputados e senadores e, também, para os próprios funcionários da empresa, dando visibilidade ao serviço prestado por todos os funcionários, desde a guarda portuária até a diretoria, mostrando a importância deles para o funcionamento da comunidade portuária.

A primeira arrendatária entrevistada representa duas arrendatárias, um terminal e um porto. A arrendatária disse possuir um site onde existe um canal identificado como "Fale conosco". Isso corresponde ao Serviço de Atendimento ao Usuário (SAU), uma exigência feita pela Agência Nacional dos Transportes Aquaviários (ANTAQ) a todos os recintos alfandegados que estão sob sua gestão. Porém, o canal se limita apenas a atendimentos aos clientes da mesma. Redes sociais não possuem função de comunicação.

Um setor de comunicação que seja voltado exclusivamente para atendimento a comunidade do entorno e comunidade em geral, é inexistente. Existe um canal informal para quando a comunidade necessita de contato com a empresa. Assim, quando um líder comunitário deseja fazer um pedido ou reclamação, ele envia um email para um endereço eletrônico específico que é direcionado à direção e à área de qualidade da empresa ou vai pessoalmente até o porto. Isso mostra que a relação é restrita a um ou poucos stakeholders. Além disso, ela é centrada em problemas sociais e ambientais prioritários e destinada somente a uma comunidade e população-alvo especifica.

A empresa admitiu que ainda é necessário uma quantidade maior de trabalhadores disponíveis para atuar na comunicação da empresa, pois é um setor que precisa ter separação do que são demandas do dia a dia relacionados aos clientes e aos serviços prestados pela empresa e demandas da população e comunidade local, que chega na forma de reclamação ou de pedidos externos. Assim, por não ter um canal efetivo de comunicação, muitas vezes essas demandas externas não chegam a quem realmente deveriam chegar, apenas quando são situações graves. Entretanto, a empresa informou que anualmente realiza treinamentos com os empregados que atuam na comunicação externa para melhorar a qualidade dos serviços prestados por ela em comunicação.

O representante das arrendatárias entrevistado declarou não receber muitas demandas da comunidade. E quando perguntado sobre qual a principal demanda da comunidade quando elas acontecem, ele informou ser a limpeza do mangue nas redondezas da empresa e da comunidade e auxílio (não especificado) a uma creche 


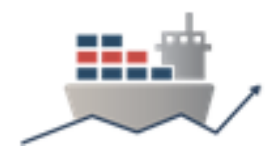

da comunidade. Isso mostra que as ações têm impacto social - contribuindo para a melhoria da qualidade de vida - e ambiental - preocupada com o meio ambiente.

Portanto, a empresa se preocupa com o bem-estar da sociedade que está ao seu redor, mas sem ter um programa de ações voltado aos problemas citados, atendendo apenas quando há demanda. Pode-se dizer, retomando o pensamento de Murray e Vogel (1997), que esse fato pode estar ligado a falta de retorno de atividades sociais que acabam sendo custosos para a empresa.

$\mathrm{Na}$ maior parte das vezes as atenções das arrendatárias estão voltadas aos seus clientes - os transportadores e exportadores/importadores. Além disso, ela também destina atenção especial aos órgãos anuentes, como a Agência Nacional de Vigilância Sanitária (ANVISA) - que é rígida na cobrança relativa a limpeza dos armazéns da empresa - e à Receita Federal, já que ambos exigem tratamento diferenciado.

Assim pode-se perceber que o foco das relações da arrendatária é muito mais interno que externo, configurando uma abordagem de responsabilidade social interna, uma vez que atende a clientes em caso de reclamações e direciona suas ações para o desenvolvimento profissional e pessoal do trabalhador, além de seu bem-estar, já que isso pode afetar os resultados da empresa, tendo consequências sobre os programas de contratação, seleção, treinamento e manutenção de pessoal.

Apesar de todas as dificuldades existentes na relação entre porto-comunidade, a empresa entrevistada diz se preocupar com a sociedade do entorno. Afinal, se o Estado passar por uma situação econômica ruim, com queda drástica de sua receita, a contribuição com os tributos ao município onde a empresa está situada também cai e quando isso ocorre os investimentos em serviços públicos como educação, transporte e segurança são afetados. Além disso, dentro da própria área portuária muitos trabalhadores são desligados, pois se faz necessário um corte de verbas da empresa e, assim, surge a situação do desemprego. Com isso as demandas da comunidade aumentam. Pode-se considerar que a relação econômica é muito forte.

As respostas obtidas da segunda arrendatária se deram através do e-mail, ficando claro que a arrendatária não possui um canal ou programa de comunicação direta com a comunidade, nem desenvolve ações para com a mesma. Os únicos meios de se conseguir comunicação com a empresa são os mais comuns de qualquer empresa: ouvidoria, fale conosco, Facebook e Linkedin. A arrendatária também afirma que dificilmente a comunidade entra em contato, a maior parte das interações são de pessoas da comunidade que vão até a empresa para deixarem currículos, todas as outras demandas são deixadas como responsabilidade da autoridade portuária, CODESA.

Afirmar que esta arrendatária possui ou não responsabilidade social é difícil, pois a mesma não abriu as portas para ser entrevistada, o que pode-se concluir pelas informações recebidas é que o investimento e preocupação com o assunto de responsabilidade social não é tão forte, deixando a responsabilidade em cima da autoridade portuária.

A quarta arrendatária entrevistada possui apenas um silo dentro de um terminal portuário, não possuindo canais de comunicação. Todas as suas demandas chegam através da autoridade portuária.

\section{CONSIDERAÇÕES FINAIS}

As empresas são agentes econômicos importantes para a economia do Estado e para isso trabalham, buscando ser sustentável financeiramente. Entretanto, esta 
deve ser apenas uma dimensão de sua atuação, já que elas também devem atuar de forma socialmente responsável buscando contribuir com a sociedade e, sobretudo, com a comunidade que a cerca. Afinal, ao atender as demandas e contribuir com o bem-estar da sociedade, ela usufrui de benefícios como a diminuição de problemas de relacionamento e melhoria de condições de trabalho, por exemplo. A população, por sua vez, apoia empresas que se preocupam com o meio ambiente e com a vida, tanto interna como externamente, ou seja, a sociedade vê com bons olhos empresas que cuidam de seus funcionários e que promovem ações sociais.

No caso em estudo pôde-se perceber que as arrendatárias que compõem o Complexo portuário de Vitória, possuem atuações muito diferentes: a primeira mostra que a responsabilidade social ainda é para ela uma questão mais interna, enquanto a segunda demonstra já compreender a importância de atuar com responsabilidade externa, apesar de suas iniciativas ainda serem pouco sistêmicas e restritas. Mas, apesar disso, na visão dela, cumpre seu papel no que se refere a promover ações externas, ajudando as comunidades do entorno.

As duas arrendatárias demonstraram compreender bem a dimensão interna da responsabilidade social, pois atuam de forma ética e legal, e se preocupam com as relações interpessoais e de valorização do trabalho de cada contratado, além de investir em treinamentos. Nem a CODESA e arrendatárias possuem dentro das suas estratégias a relação com a comunidade no entorno e nem ações para que promova melhorias e bem-estar de forma voluntária.

Como a CODESA é a autoridade portuária e responsável pelo arrendamento de sua área, percebe-se que as arrendatárias tiram suas responsabilidades de empresa perante as comunidades do entorno, passando a CODESA como membro responsável pela comunicação, ações e estratégias.

A interação entre as arrendatárias é, entretanto, um fator que merece maior aprofundamento, já que as duas atuam na mesma comunidade. Mas os fatores que fazem com que isso não aconteça, devem ser alvo de outro estudo. Portanto, o assunto não se encontra encerrado. Há ainda muito a ser explorado utilizando esta metodologia para melhor compreensão da relação Porto e Cidade, deve ser dado continuidade ao estudo através de pesquisas com a comunidade e demais stakeholders.

\section{REFERÊNCIAS}

ALBUQUERQUE, José de Lima. Gestão ambiental e responsabilidade social: conceitos, ferramentas e aplicações. São Paulo: Atlas, 2009.

ASHLEY, P., QUEIROZ, A., CARDOSO, A., SOUZA, A., TEODÓSIO, A., \& BORINELLE, B. et al. Ética e responsabilidade social nos negócios. Rio de Janeiro: Saraiva, 2003.

BELINKY, Aron; MATTAR, Hélio. Pesquisa Akatu 2012 Rumo à Sociedade do BemEstar: Assimilação e Perspectivas do Consumo Consciente no Brasil - Percepção da Responsabilidade Social Empresarial pelo Consumidor Brasileiro. São Paulo: Instituto Akatu, 2013. Disponível em: https://www.akatu.org.br/wpcontent/uploads/2017/04/PESQUISAAKATU.pdf Acesso em: 12-ago.- 2019.

BERTONCELLO, Silvio Luiz Tadeu; JÚNIOR, João Chang. A importância da Responsabilidade Social Corporativa como fator de diferenciação. FACOM, n.
17 .
p.
74 ,
2007.
Disponível
em: 


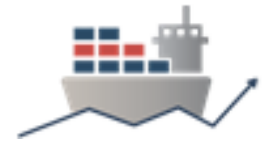

http://www.ead.aedb.br/joomla/mat35/images/artigos/aimportanciadarsc. pdf>.

Acesso em: 24 junho 2019.

BOWER, H. R. Responsabilidades sociais dos homens de negócio. Rio de Janeiro: Editora Civilização Brasileira S.A, 1957.

CARRIGAN, Marylyn; ATTALLA, Ahmad. The Mithy of the ethical consumer - Do ethics matter in purchase behaviour?. Journal of Consumer Marketing, v. 18, n. 7, p. 560-577, 2001. Disponível em: $<$ https://www.researchgate.net/publication/243461925_The_myth_of_the_ethical_co nsumer_-_Do_ethics_matter_in_purchase_behaviour>- Acesso em: $\overline{2} 4$ junho 2019.

CODESA. Porto de Vitoria - Autoridade Portuária. Vitoria, 20 ago. 2013. Disponível em < http://www.codesa.gov.br/site/. $>$ Acesso em: 01 nov. de 2013.

FARIA, Alexandre; SAUERBRONN, Fernanda Filgueiras. A responsabilidade social é uma questão de estratégia? Uma abordagem crítica. RAP Revista de Administração Pública, Rio de Janeiro, jan/fev. 2008. ISSN 0034-7612. Disponível em: < http://www.scielo.br/pdf/rap/v42n1/a02v42n1.pdf>. Acesso em: 27 fevereiro 2019.

GALBREATH, Jeremy. Building Corporate Social Responsibility Into Strategy. Disponível em: <https://espace.curtin.edu.au/bitstream/handle/20.500.11937/35406/132780_132781. pdf? sequence=2>. Acesso em: 10 julho 2019.

GARCIA, Bruno Gaspar (et. al.). Responsabilidade social das empresas: a contribuição das universidades. Volume 5. Prêmio Ethos Valor, 5 ed. São Paulo: Peirópolis/ Instituto Ethos, $2002 . \quad$ Disponível em: <https://books.google.com.br/books?id=6w59TJdcpMgC\&pg=PA3\&dq=ethos+Respo nsabilidade+Social+nas+empresas:+a+contribui\%C3\%A7\%C3\%A3o+das+universida des\&hl=pt-

BR\&source=gbs_selected_pages\&cad $=2 \# v=$ onepage \& $q=$ ethos $\% 20$ Responsabilidad e\%20Social\%20nas\%20empresas $\% 3 A \% 20$ a\%20contribui\%C3\%A7\%C3\%A3o\%20d as\%20universidades\&f=false $>$. Acesso em: 05 fevereiro 2019.

GUIMARÃES, Heloisa Werneck Mendes. Responsabilidade social da empresa: uma visão histórica de sua problemática. Ver. Adm. Empres. São Paulo, v. 24, n. 4, p. 211-219, Dec. 1984 . Disponível em: <http://www.scielo.br/scielo.php?script=sci_arttext\&pid=S0034$75901984000400031 \&$ Ing=en\&nrm=iso>. Acesso em: 29 abril 2018.

KREITLON, Maria Priscilla. A Ética nas Relações entre Empresas e Sociedade: Fundamentos Teóricos da Responsabilidade Social Empresarial. Disponível em: < http://www.anpad.org.br/admin/pdf/enanpad2004-gsa-2651.pdf>. Acesso em: 10 março 2019.

MAC LENNAN, Maria Laura Ferranty, SEMENSATO, Bárbara Ilze, OLIVA, Fábio Lotti. RESPONSABILIDADE SOCIAL EMPRESARIAL: CLASSIFICAÇÃO DAS INTITUIÇÕES DE ENSINO SUPERIOR EM REATIVAS OU ESTRATÉGICAS SOB A ÓTICA DA GOVERNAÇA CORPORATIVA. REGE Revista de Gestão, São Paulo, v. 22, n. 4, p. 457-472, feb. 2016. ISSN 2177-8736. Disponível em: <http://www.revistas.usp.br/rege/article/view/111499/109635>. Acesso em: 22 maio 2018. 
VI CIDESPORT/2019

Congresso Internacional

de Desempenho Portuário

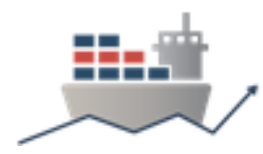

MATTEDI, José Carlos. Alma de portuário: história do Porto de Vitória. Vitória, ed do autor, 2018.

MELO NETO, F. P., \& FROES, C. Gestão da responsabilidade social corporativa: o caso brasileiro. Rio de Janeiro: Editora Qualitymark, 2001.

PORTER, Michael E.; KRAMER, Mark R. Strategy and society: the link between competitive advantage and corporate social responsibility. Harvard Business Review, Dezembro, 2006.2 Disponível em:<https://www.sharedvalue.org/sites/default/files/resourcefiles/Strategy_and_Society.pdf>. Acesso em: 27 Fevereiro 2019.

REIS, Carlos. A responsabilidade social das empresas: o contexto brasileiro em face da ação consciente ou do modernismo do mercado?. Disponível em: <http://www.scielo.br/pdf/rec/v11n2/a04v11n2> Acesso em: 29 abril 2018.

SCHROEDER, Jocimari. Responsabilidade social corporativa: Limites e possibilidades. Disponível em: < http://www.scielo.br/pdf/raeel/v3n1/v3n1a01> Acesso em: 29 abril 2018.

SEN, Amartya; KLIKSBERG, Bernardo. As pessoas em primeiro lugar: a ética do desenvolvimento e os problemas do mundo globalizado. São Paulo: Companhia das Letras, 2010.

SERPA, Daniela Abrantes Ferreira; FOURNEAU, Lucelena Ferreira. Responsabilidade social corporativa: uma investigação sobre a percepção do consumidor. Rev. adm. contemp., Curitiba, v. 11, n. 3, p. 83-103, Sept. 2007. Disponível em: <http://www.scielo.br/scielo.php?script=sci_arttext\&pid=S141565552007000300005\&lng=en\&nrm=iso>. Acesso em: 29 abril 2018.

SMITH, C. The new corporate philanthropy. Harvard Business Review, 72(3), 105116. 1994

TENÓRIO, Fernando Guilherme. Responsabilidade Social: teoria e prática. 2 ed. rev. e ampl. Rio de Janeiro: FGV, 2006.

VASCONCELOS, Flavia Nico. O desenvolvimento da interface cidade-porto em Vitória (ES) do período colonial ao início do século XXI: uma cidade portuária? 2011. 463 f. Tese (Doutorado em Ciências Sociais) - Pontifícia Universidade Católica de São Paulo, São Paulo, 2011.

\section{AGRADECIMENTOS;}

As autoras agradecem a Fundação de Amparo à Pesquisa e Inovação do Espírito Santo - FAPES pela oportunidade de elaborar a presente pesquisa, nos termos do Edital Universal . 03/2017 - Universal. 